\title{
PERBANDINGAN ANTARA ORGANIZATIONAL CITIZENSHIP BEHAVIOR DENGAN TINGKAT KEMATANGAN DOSEN. STUDI PADA DOSEN POLITEKNIK NEGERI BANJARMASIN
}

\author{
Nurfitriah, S.Pd., M.A ${ }^{(1)}$, Sari Hepy Maharani, SE., M.M ${ }^{(2)}$ \\ (1) nurfitriah@poliban.ac.id, ${ }^{(2)}$ sarihepymaharani@poliban.ac.id \\ (1) Staf Pengajar Jurusan Teknik Sipil, Politeknik Negeri Banjarmasin, (2) Pengajar \\ Jurusan Administrasi Bisnis, Politeknik Negeri Banjarmasin
}

Ringkasan

This research aims to find out whether lecturers with different maturity levels have different OCBs. Research was conducted on 120 lecturers of State Polytechnic of Banjarmasin. Data analysis was done descriptively and quantitatively using One Way ANOVA. The analysis shows that OCB differs at different maturity levels, the increase in OCB is proportional to the increase in maturity level.

Kata kunci: Comparison, Organizational Citizenship Behavior, Maturity Level.

\section{A. PENDAHULUAN}

Hasil Penelitian Pusat Informatika Departemen Pendidikan dan Kebudayaan, menunjukkan bahwa guru (dosen) yang berkualitas mempunyai hubungan dengan kualitas pendidikan (Depdikbud, 1994).

Kualitas dosen diukur dari tercapainya Tridharma Perguruan Tinggi. Namun dalam kenyataannya, setiap dosen memiliki bebagai keterbatasan dalam pelaksanaan tugasnya sehingga membutuhkan perilaku ekstra peran dari teman sejawat yang dikenal dengan organizational citizenship behavior (OCB). Sehingga dapat disimpulkan bahwa karyawan/dosen yang memiliki perilaku OCB bisa berkontribusi lebih dalam pencapaian tujuan perusahaan/perguruan tinggi (Bolino and Turnley, 2003) bahkan sangat penting dalam suatu fungsi organisasi (Bateman and Organ, 1983; Organ, 1988; Hazratian et al, 2015; MAN, Mihaela, 2016; Muthurahman \& Al-Haziazi, 2017).

Menurut Organ dkk (2006). OCB adalah perilaku yang bersifat bebas yang tidak secara langsung dan eksplisit mendapat penghargaan dari system imbalan formal. OCB juga disebut sebagai perilaku ekstra anggota organisasi yang secara aggregate meningkatkan fungsi efektif organisasi. perilaku OCB meliputi membantu individu lain dalam tim, mengajukan diri untuk melakukan pekerjaan ekstra, menghindari konflik yang tidak perlu, menghormati semangat dan segala peraturan kampus. Memiliki inisiatif dan peran yang lebih diluar job description atau perilaku OCB dapat memberi pengaruh positif bagi eksistensi organisasi dalam hal peningkatan produktivitas rekan kerja, peningkatan produktivitas pemimpin, penghematan sumber daya, pemeliharaan fungsi kelompok, peningkatan stabilitas kerja organisasi dan kemampuan organisasi untuk beradaptasi dengan perubahan lingkungan (Fitrianasari, 2007).

Telah banyak studi yang dilakukan sehubungan dengan anticedents OCB dan efek dari OCB. Studi Shore dan Wayne (1993) menemukan bahwa persepsi terhadap dukungan organisasional (Perceived Organizational Support/POS) dapat menjadi prediktor Organizational Citizenship Behavior (OCB). Pekerja yang merasa bahwa mereka didukung organisasi akan memberikan umpan balik (feedback) dan menurunkan ketidakseimbangan dalam hubungan tersebut dengan terlibat dalam perilaku citizenship. Kualitas interaksi atasan dan bawahan; persepsi terhadap kualitas interaksi atasanbawahan merupakan faktor yang menyebabkan organizational citizenship behavior karyawan. Makin tinggi persepsi terhadap kualitas interaksi atasan-bawahan, maka makin tinggi OCB karyawan.

Faktor kesediaan atasan menggunakan otoritasnya untuk membantu bawahan memecahkan masalah yang dihadapi bawahan memecahkan masalah yang dihadapi merupakan faktor paling dominan dalam mempengaruhi OCB (Novliadi, 2006).

Menurut Wayne, Shore, dan Leden (1997), karyawan yang memiliki kualitas interaksi yang tinggi dengan atasannya dapat mengerjakan pekerjaan selain yang biasa mereka lakukan. Sedangkan karyawan yang 
memiliki kualitas interaksi yang rendah dengan atasannya lebih cenderung menujukkan pekerjaan yang rutin saja dari sebuah kelompok kerja.

Sommer, Bae, dan Luthans (1996) mengemukakan masa kerja dapat berfungsi sebagai prediktor OCB karena variable-variabel tersebut mewakili "pengukuran" terhadap "investasi" karyawan di organisasi.

Morrison (1994) membuktikan bahwa ada perbedaan persepsi terhadap OCB antara pria dan wanita. Wanita menganggap OCB merupakan bagian dari perilaku in-role mereka dibanding pria. Bukti-bukti tersebut menunjukkan bahwa wanita cenderung menginternalisasi harapan-harapan kelompok, rasa kebersamaan, dan aktivitas-aktivitas menolong sebagai bagian dari pekerjaan mereka (Diefendorff, Brown, Kamin, \& Lord, 2002).Yogamalar \& Samuel (2016) mengemukakan bahwa OCB pada generasi yang berbeda memiliki nilai yang berbeda pula. Kvitne (2017) menyatakan bahwa perkembangan OCB pada setiap individu berbeda tergantung dengan psikologi individu tersebut. Soo \& Ali (2017) menjelaskan bahwa faktor stress atau emosi seorang karyawan akan mempengaruhi OCBnya.

Sayangnya, berdasarkan pengamatan, ada beberapa indikasi yang menunjukkan bahwa organizational citizenship behavior para dosen di Politeknik Negeri Banjarmasin belum optimal. Beberapa hal yang mengindikasikan belum optimalnya OCB dosen Politeknik Negeri Banjarmasin adalah adanya pengakuan dosen yang mengalami kesulitan dalam menyampaikan matakuliahnya terkait dengan metode pembelajaran dan daya tangkap mahasiswa, dosen belum mempunyai inisiatif dan ide untuk mengembangkan potensinya dan untuk mengatasi masalah-masalah yang dihadapinya (masih menunggu perintah dan inisiatif dari atasan atau institusi), masih banyak dosen yang tidak mengikuti pertemuan rutin seperti rapat anggota tahunan koperasi atau forum silaturrahmi, merupakan sebagian contoh indikasi belum optimalnya kinerja ekstra peran ini.

Luo \& Liu (2014) menyatakan bahwa kepemimpinan situasional atau pemimpin yang mampu menyesuaikan gaya kepemimpinannya sesuai dengan tingkat kematangan karyawan dapat meningkatkan OCB. Namun dalam kenyataannya hingga saat ini belum ada yang mengukur apakah OCB pada tingkat kematangan yang berbeda juga berbeda. Oleh karena itu, penelitian ini bertujuan untuk mengetahui apakah OCB dosen berbeda pada tingkat kematangan yang berbeda.

\section{B. LANDASAN TEORI}

\section{OCB (Oganizational Citizenship Behavior)}

Dimensi organizational citizenship

behavior menurut Organ (2006) adalah altruism, conscientiousness, sportsmanship, courtesy dan civic virtue. Altruism merupakan perilaku karyawan dalam menolong rekan kerjanya yang mengalami kesulitan dalam situasi yang sedang dihadapi baik mengenai tugas dalam organisasi maupun masalah pribadi dengan orang lain. Dimensi ini mengarah kepada memberi pertolongan yang bukan merupakan kewajiban yang ditanggungnya. Bukhari, Ali, Shahzad, dan Bashir (2009); Sharma \& Jain (2014) mengatakan jika karyawan dalam suatu organisasi memiliki antusiasme untuk membantu satu sama lain dan tidak mementingkan diri sendiri dalam mencapai tujuan organisasi, secara alami akan meningkatkan OCB dalam organisasi. Contohnya adalah perilaku seperti membantu seorang rekan yang tidak masuk kerja, membantu orang lain yang memiliki beban kerja berat, memerhatikan perilaku seseorang memengaruhi pekerjaan orang lain, dan menyediakan bantuan dan dukungan untuk karyawan baru merupakan indikasi yang jelas tentang lingkungan kerja (Pare' \& Tremblay, 2000). Sementara conscientiousness adalah perilaku yang ditunjukkan dengan berusaha melebihi yang diharapkan perusahaan, misalnya efesiensi penggunaan waktu dan melampaui harapan, perilaku sukarela yang bukan merupakan kewajiban atau tugas karyawan. Dimensi ini menjangkau jauh di atas dan jauh ke depan dari panggilan tugas. Seseorang yang sadar akan tanggung jawabnya secara sukarela mengambil tanggung jawab ekstra, tepat waktu, menempatkan kepentingan pada keterperincian dan kualitas tugas, dan secara umum mengerjakan di atas dan jauh melebihi panggilan tugas. Lalu sportsmanship adalah perilaku yang memberikan toleransi terhadap keadaan yang kurang ideal dalam organisasi tanpa mengajukan keberatan-keberatan. Seseorang yang mempunyai tingkatan yang tinggi dalam sportsmanship akan meningkatkan iklim yang positif di antara karyawan. Karyawan akan lebih sopan dan bekerja sama dengan yang lain sehingga akan menciptakan lingkungan kerja yang lebih menyenangkan. Contoh perilakunya antara lain kemauan untuk bertoleransi tanpa mengeluh, menahan diri dari aktivitas-aktivitas mengeluh dan mengumpat, tidak mencari-cari kesalahan dalam organisasi, dan tidak mengeluh tentang segala sesuatu, serta tidak membesar-besarkan permasalahan di luar proporsinya. Kemudian courtesy adalah 
menjaga hubungan baik dengan rekan kerjanya agar terhindar dari masalah interpersonal. Seseorang yang memiliki dimensi ini adalah orang yang menghargai dan memerhatikan orang lain. Contoh perilaku dalam kategori ini adalah secara berkala memahami rekan kerja untuk mencari tahu bagaimana pekerjaan akan berjalan, atau membiarkan orang lain tahu bagaimana mencapainya (Jex, 2002). Terakhir, civic virtue merupakan perilaku yang mengindikasikan tanggung jawab pada kehidupan organisasi (mengikuti perubahan dalam organisasi, mengambil inisiatif untuk merekomendasikan bagaimana operasi atau prosedur-prosedur organisasi dapat diperbaiki dan melindungi sumber-sumber yang dimiliki oleh organisasi). Dimensi ini mengarah pada tanggung jawab yang diberikan organisasi kepada seorang untuk meningkatkan kualitas bidang pekerjaan yang ditekuni. Civic virtue dapat dijelaskan sebagai kesediaan karyawan untuk terlibat dalam hal-hal yang rutin maupun tidak rutin pada organisasi untuk menciptakan kesan baik dari organisasi (Bukhari et al., 2009). Contoh perilaku adalah menghadiri pertemuan rutin atau rapat, membaca dan menjawab email yang berhubungan dengan pekerjaan, dan berpartisipasi dalam kegiatan organisasi.

\section{Maturity/Kematangan}

Menurut Hersey dan Blanchard (2002), kematangan dibagi menjadi empat tingkatan yang berbeda:

1. M1 - Orang-orang pada tingkat kematangan berada pada tingkat bawah skala. Mereka kekurangan pengetahuan, keterampilan, atau kepercayaan diri untuk bekerja sendiri, dan mereka perlu didorong untuk melakukan tugasnya. Ciri-ciri karyawan pada tingkat ini tidak melakukan tugas pada level yang dapat diterima, terindimidasi oleh tugasnya, tidak jelas mengenai arah tugas, penundaan pelaksanaan tugas, mengajukan sejumlah pertanyaan mengenai tugas, menghindari tugas, atau, menjadi defensif atau tidak enak untuk melaksanakan tugas.

2. M2 - pada tingkat ini, karyawan mungkin bersedia mengerjakan suatu tugas, namun tetap tidak memiliki keterampilan untuk menyelesaikannya dengan sukses. Ciri-ciri karyawan pada tingkat ini adalah tertarik dan responsif, menunjukkan kemampuan sedang, mau menerima masukan, penuh perhatian, antusiastik, mau melaksanakan tugas baru tanpa pengalaman.

3. M3 - Di sini, para pengikut siap dan bersedia membantu tugas tersebut. Mereka memiliki keterampilan lebih dari kelompok M2, tapi mereka masih belum percaya diri dengan kemampuan mereka. Ciri-ciri karyawan pada tingkat ini adalah telah menunjukkan pengetahuan dan kemampuan, tampak ragu-ragu untuk menyelesaikan atau mengambil langkah berikutnya dalam melaksanakan tugas, kelihatannya takut, kaget dan bingung, tampak masa bodoh untuk melaksanakan tugas sendiri, sering meminta pulang lebih awal

4. M4 - Pengikut ini bisa bekerja sendiri. Mereka memiliki keyakinan yang kuat dan keterampilan yang tinggi, serta komitmen terhadap tugas. Ciri-ciri karyawan pada tingkat ini adalah membuat atasan selalu terinformasi tentang kemajuan pelaksanaan tugas, mempergunakan sumber secara efisien, bertanggungjawab dan berorientasi pada hasil, dapat melaksanakan tugas secara independen, berbagi berita baik dan buruk, membuat keputusan yang efektif mengenai tugas, melaksanakan standar tinggi, berbagi ide kreatif, menyelesaikan tugas tepat waktu atau lebih cepat.

Maturity Levels

\begin{tabular}{|l|c|c|c|}
\hline \multicolumn{1}{|c|}{ High } & \multicolumn{2}{|c|}{ Moderate } & Low \\
\hline \multicolumn{1}{|c|}{ M4 } & M3 & M2 & M1 \\
\hline $\begin{array}{l}\text { Very capable and } \\
\text { confident }\end{array}$ & Capable but unwilling & Unable and willing & Unable but insecure \\
\hline
\end{tabular}

Sumber : Hersey \& Blanchard (2002)

\section{METODE PENELITIAN}

Penelitian survei dilakukan kepada 120 orang dosen Politeknik Negeri Banjarmasin. Variabel yang digunakan dalam penelitian ini adalah vaiabel OCB dan Kematangan Dosen. Variabel OCB (Organ, 2006) meliputi altruism, conscientiousness, sportsmanship, courtesy dan civic virtue. indikator:

Altruism diukur dengan menggunakan

1. menolong rekan kerja yang mengalami kesulitan

2. memberi pertolongan yang bukan merupakan kewajiban yang ditanggung dosen.

Conscientiousness diukur dengan menggunakan indikator

1. berusaha bekerja melebihi yang diharapkan lembaga, perilaku sukarela yang bukan merupakan kewajiban atau tugas dosen

2. bekerja menjangkau jauh diatas atau jauh ke depan dari panggilan tugas dosen.

Sportsmanship diukur dengan menggunakan indikator

1. memberikan toleransi terhadap keadaan yang kurang ideal dalam organisasi tanpa mengajukan keberatan-keberatan 
2. seseorang yang mempunyai tingkatan yang tinggi dalam iklim yang positif di antara dosen

3. dosen akan lebih sopan dan bekerja sama dengan yang lain sehingga akan menciptakan lingkungan kerja yang lebih menyenangkan. indikator

Courtesy diukur dengan menggunakan

1. menjaga hubungan baik dengan rekan kerja agar terhindar dari masalah-masalah interpersonal

2. menghargai dan memperhatikan orang lain. indikator

Civic virtue diukur dengan menggunakan

1. tanggung jawab pada kehidupan organisasi

2. mengikuti perubahan dalam organisasi

3. mengambil inisiatif untuk merekomendasikan prosedur-prosedur organisasi agar dapat diperbaiki

4. melindungi sumber-sumber yang dimiliki oleh organisasi untuk meningkatkan kualitas pekerjaan yang ditekuni.

Keseluruhan indikator tersebut diukur dengan menggunakan skala Likert.

Sedangkan variabel kematangan (Hershey \& Blanchard, 2002) meliputi kematangan kerja dan kematangan jiwa. Kematangan jiwa diukur melalui indikator kepercayaan diri dalam melaksanakan pekerjaan, komitmen dalam bekerja, dan motivasi dalam menyelesaikan pekerjaan. Sedangkan kematangan kerja diukur melalui indikator pengetahuan mengenai pekerjaan, pengalaman dalam bekerja, serta ketampilan dalam bekerja. Indikator diukur dengan menggunakan skala Likert.

Poses analisis data yang petama kali dilakukan adalah dengan menggunakan uji validitas dan reliabilitas. Selanjutnya dosen yang menjadi sampel penelitian dikelompokkan kedalam 4 kategori kematangan yaitu M1, M2, M3 dan M4 (Maturity/ Kematangan 1, Maturity/ Kematangan 2, Maturityl Kematangan 3, Maturityl Kematangan 4). Pengelompokan didasarkan atas nilai minimun dan maksimum dari kuesioner kematangan, kemudian dihitung nilai pesentilnya untuk dijadikan batasan antar kelompok.

Langkah selanjutnya dilakukan uji homogenitas untuk membandingkan varian nilai OCB dosen pada masing-masing tingkat kematangan.

Langkah terakhir OCB masing-masing kelompok dibandingkan dan dianalisis menggunakan One Way ANOVA. Analisis ini digunakan untuk mengetahui apakah ada perbandingan nyata pada rata-rata OCB dosen diantara tingkat kematangan yang berbedabeda.

\section{HASIL DAN PEMBAHASAN Analisis Deskriptif}

Berikut ini adalah data deskiptif tentang nilai OCB dosen yang berada 4 tingkat kematangan yang berbeda :

Tabel Frekuensi dan Rata-rata Tingkat Kematangan Dosen

\begin{tabular}{|c|c|c|}
\hline Tingkat Kematangan & Jumlah & $\begin{array}{c}\text { Mean } \\
\text { OCB }\end{array}$ \\
\hline M1 & 42 & 95.3333 \\
\hline M2 & 34 & 101.0000 \\
\hline M3 & 34 & 107.4118 \\
\hline M4 & 10 & 107.8000 \\
\hline
\end{tabular}

\section{Sumber : Data diolah, 2018}

Data diatas menunjukkan bahwa sebagian besar dosen Poliban yang menjadi sampel penelitian (110 orang) berada dalam tingkat kematangan M1, M2, M3. Sedangkan yang berada pada tingkat kematangan M4 hanya 10 orang. Artinya dari 120 orang dosen yang menjadi sampel hanya 10 orang saja yang benar-benar memiliki skill/knowledge yang tinggi dan berkomitmen terhadap tugas. Sedangkan sisanya masih belum benar-benar memiliki skill ataupun komitmen yang tinggi terhadap tugas yang dibeikan atasan.

\section{Grafik Rata-rata OCB}

Pada Bebagai Tingkat Kematangan $\backslash$

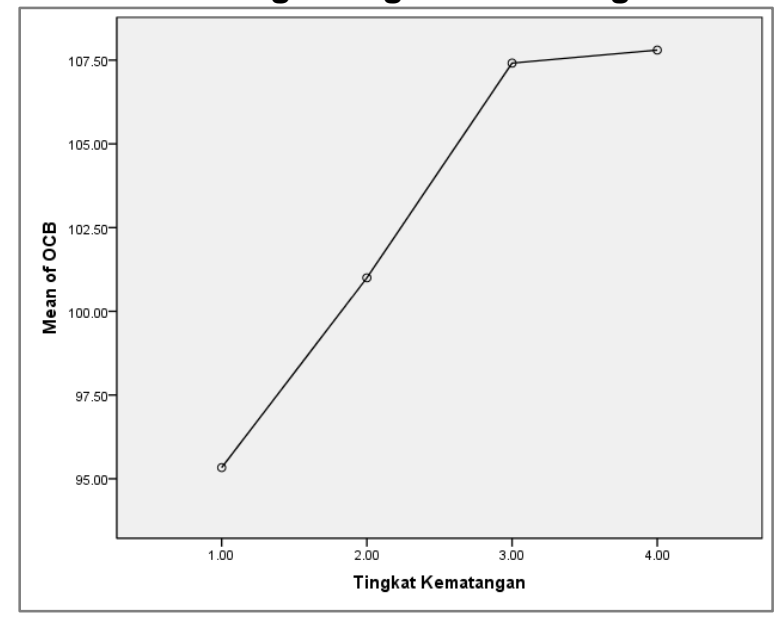

Sumber : Data diolah, 2018

Senada dengan tabel diatas, grafik diatas menunjukkan menunjukkan bahwa rata-rata OCB dosen meningkat seiring dengan meningkatnya tingkat kematangan dosen.

\section{Uji Validitas dan Reliabilitas}

Ringkasan hasil uji validitas dan relibilitas dapat dilihat pada tabel dibawah ini : 
Tabel Hasil Uji Validitas

\begin{tabular}{|c|c|c|c|}
\hline variabel & nilai $r$ & variabel & nilai $r$ \\
\hline KK.1 & .428 & OCB.1 & .511 \\
\hline KK.2 & .486 & OCB.2 & .451 \\
\hline KK.3 & .320 & OCB.3 & .609 \\
\hline KK.4 & .617 & OCB.4 & .641 \\
\hline KK.5 & .669 & OCB.5 & .739 \\
\hline KK.6 & .552 & OCB.6 & .654 \\
\hline KK.7 & .530 & OCB.7 & .605 \\
\hline KK.8 & .707 & OCB.8 & .831 \\
\hline KK.9 & .845 & OCB.9 & .629 \\
\hline KK.10 & .524 & OCB.10 & .517 \\
\hline KK.11 & .539 & OCB.11 & .716 \\
\hline KJ.1 & .724 & OCB.12 & .778 \\
\hline KJ.2 & .433 & OCB.13 & .613 \\
\hline KJ.3 & .557 & OCB.14 & .578 \\
\hline KJ.4 & .527 & OCB.15 & .573 \\
\hline KJ.5 & .615 & OCB.16 & .521 \\
\hline KJ.6 & .754 & OCB.17 & .688 \\
\hline KJ.7 & .646 & OCB.18 & .572 \\
\hline KJ.8 & .625 & OCB.19 & .507 \\
\hline KJ.9 & .578 & OCB.20 & .815 \\
\hline KJ.10 & .592 & OCB.21 & .755 \\
\hline KJ.11 & .681 & OCB.22 & .616 \\
\hline KJ.12 & .615 & OCB.23 & .715 \\
\hline KJ.13 & .612 & OCB.24 & .577 \\
\hline & & OCB.25 & .511 \\
\hline & & OCB.26 & .656 \\
\hline
\end{tabular}

Sumber : Data diolah, 2018

Uji validitas digunakan untuk mengukur tepat atau tidaknya suatu item pertanyaan. Syarat lolos uji ini adalah nilai $r$ hitung $>r$ tabel. Diperoleh nilai tabel sebesar 0,1793 . Sehingga dapat disimpulkan bahwa seluuh variabel diatas lolos uji validitas.

Tabel Hasil Uji Reliabilitas

\begin{tabular}{|l|r|}
\hline \multicolumn{1}{|c|}{ Variabel } & Nilai alpha Cronbach \\
\hline Kematangan dosen & 0.917 \\
\hline OCB & 0.935 \\
\hline
\end{tabular}

Sumber : Data diolah, 2018

Uji reliabilitas digunakan untuk mengukur konsistensi pertanyaan dari suatu kuesioner. Syarat lolos uji ini adalah nilai alpha cronbach $>0,7$. Sehingga dapat disimpukan bahwa variabel kematangan dan OCB dalam penelitian ini reliabel.
Uji Homogenitas

Tabel Uji Homogenitas
Test of Homogeneity of Variances
\begin{tabular}{|c|r|r|r|}
\hline OCB & Levene \\
Statistic & df1 & df2 & Sig. \\
\hline 3.041 & 3 & 116 & .032 \\
\hline
\end{tabular}

Sumber : data diolah, 2018

Uji Homogenitas digunakan untuk mengetahui apakah vaRian nilai OCB pada 4 tingkat kematangan berbeda atau tidak. Nilai $p$ value/signifikansi sebesar 0.032 menunjukkan bahwa varian nilai OCB pada 4 tingkat kematangan tersebut berbeda. Hal tersebut disebabkan oleh berbedanya jumlah dosen yang ada pada tingkat kematangan tersebut. Dosen yang berada pada tingkat kematangan M1 ada 42 orang, sebaliknya dosen yang berada pada tingkat kematangan M4 hanya 10 orang.

\section{Analisis One Way ANOVA}

\section{Tabel hasil Analisis One Way ANOVA}

\begin{tabular}{|c|c|c|c|c|c|}
\hline \multicolumn{6}{|c|}{ ANOVA } \\
\hline & $\begin{array}{l}\text { Sum of } \\
\text { Squares }\end{array}$ & df & Mean Square & $\mathrm{F}$ & Sig. \\
\hline Between Groups & 3189.631 & 3 & 1063.210 & 9.053 & .000 \\
\hline Within Groups & 13623.169 & 116 & 117.441 & & \\
\hline Total & 16812.800 & 119 & & & \\
\hline
\end{tabular}

Sumber : Data diolah, 2018

Analisis One Way ANOVA digunakan untuk mengetahui adanya perbandingan yang nyata pada OCB dosen untuk 4 tingkat kematangan yang bebeda. Hasil analisis menunjukkan nilai $p$ value sebesar 0,000 (dibawah 0,05 ) yang artinya adalah bahwa OCB dosen pada 4 tingkat kematangan berbeda secara nyata.

\section{Batasan Penelitian}

Kendala dalam penelitian ini adalah sulitnya menentukan jumlah dosen yang sama untuk masing-masing kelompok kematangan. Hal ini disebabkan karena survei pengukuran kematangan dan OCB dosen dilakukan secara bersama-sama. Sehingga jumlah dosen dalam masing-masing kelompok kematangan tidak dapat ditentukan. Hal ini berpengaruh terhadap uji normalitas data (data tidak berdistribusi normal).

\section{E. PENUTUP Kesimpulan}

Dari hasil penelitian dan pembahasan dapat disimpulkan bahwa OCB dosen berbeda pada tingkat kematangaan dosen yang berbeda pula. Analisis deskriptif mempekuat temuan ini 
dengan menunjukkan bahwa semakin tinggi tingkat kematangan dosen maka semakin tinggi OCB dosen.

Hasil analisis ini dapat membantu pihak manajemen universitas untuk memilih orangorang dengan tingkat kematangan yang tinggi untuk menerima tanggung jawab yang lebih besar bagi kelompoknya. Orang-orang yang tepat (tingkat kematangan tinggi, OCB tinggi) dapat melaksanakan tugas dan tanggung jawab lebih baik dengan pengawasan yang longgar. Hal ini tentunya $m$ eningkatkan efisiensi pihak manajemen dalam hal pengawasan namun tetap dapat menghasilkan pekerjaan yang berkualitas.

\section{Saran}

Meskipun dalam penelitian ini dapat dilihat bahwa OCB dosen pada tingkat kematangan yang berbeda memiliki nilai/hasil yang berbeda namun untuk memperkuat hasil penelitian perlu dilakukan analisis korelasi antara tingkat kematangan dosen dengan OCB dosen.

\section{F. DAFTAR PUSTAKA}

1. Bateman, T.S. and Organ, D.W. (1983), "Job satisfaction and the good soldier: the relationship between affect and employee "citizenship", Academy of Management Journal, Vol. 26, pp. 587-95.

2. Bolino, M.C. and Turnley, W.H. (2003), "Going the extra mile: cultivating and managing employee citizenship behavior", Academy of Management Executive, Vol. 17 No. 3, pp. 60-71. -Bolino.

3. Bukhari, Z. U., Ali, U., Shahzad, K., and Bashir, S. (2009). Determinants of organizational citizenship behavior in Pakistan. International Review of Business Research Papers, 5(2), 132-150.

4. Diefendorff, J. M., Brown, D. J., Kamin, A. M., and Lord, R. G. (2002). Examining the roles of job involvement and work centality in predicting organizational citizenship behaviors and job performance. Journal of Organizational Behavior, 23(1), 93-108. Jex, S. M. (2002). Organizational psychology a scientist-practitioner aproach. New York: John Wiley \& Sons.

5. Hazratian, Teimour., Khadivi, Asdullah., Abbasi, Beytollah., Ghojazadeh, Morteza. (2015). Association Between Organizational Citizenshtip Behavior and Educational Performance of Faculty Members in Tabriz University of Medical Science in 2014. Res Dev Med Educ, 2015, 4(1), 81-84.

6. Hersey, Paul \& Blanchard, Ken, (2002), Manajemen Perilaku Organisasi:
Pendayagunaan SumberDaya Manusia, EdisiKeempat. Penerjemah Agus Dharma, Penerbit Erlangga, Jakarta.

7. Kvitne, Maylinn Bidne.(2017) Development of Organizational Citizenship Behavior and The Effect of Psychological Contract Fulfillment. Master Thesis at Department of Psychology, Oslo University

8. Luo, H., \& Liu, S. (2014). Effect of situational leadership and employee readiness match on organizational citizenship behavior in China. Social Behavior and Personality: An international journal, 42, 1725-1732.

9. MAN, Mihaela.(2016). Managers and Organizational Citizenship Behavior. Buletin Steintific Nr. 1(41), 2016. University lasi Romania.

10.Muthuraman, Subrahmanian., Al-Haziazi, Mohammed. (2017) Examining The Factors of Organizational Citizenship Behavior with Reference to Corporate Sector in Sultanate Oman. International Review of Management and Marketing, 2017, 7(1), 413-422.

11.Morrison, E. W. (1994). Role definition and organizational citizenship behavior: The importance of the employee's perspective. Academy of Management Journal, 37(6), 1543-1567. Organ, D.W. (1988), Organizational Citizenship Behavior: The Good Soldier Syndrome, Lexington Books, Lexington, MA.

12.Novliadi, F. (2006). Organizational citizenship behavior karyawan ditinjau dari persepsi terhadap kualitas interaksi atasanbawahan dan persepsi terhadap dukungan organisasional. Psikologia, 2(1), 39-46.

13.Organ, D. W. 2006. Organizational Citizenship Behavior: The Good Soldier Syndrome. Lexington, MA: Lexington Books.

14.Pare', G., and Tremblay, M. (2000). The measurement and antecedent of turnover intention among IT professionals. Scientific Series.http://www.cirano.qc.ca/pdf/publicatio n/2000s-33.pdf

15.Sharma, V., Jain, S. (2014), A scale for measuring organizational citizenship behavior in manufacturing sector. Pacific Business Review International, 6(8), 57-62.

16.Shore, L. M., and Wayne, S. J. (1993). Commitment and employee behavior: Of affective commitment and continuance commitment with perceived organizational support. Journal of Applied Psychology, 78(5), 774-780.

17.Sommer, S. M., Bae, S. H., and Luthans, F. (1996). Organizational commitment across cultures: The impact of antecedents of Korean. Human Relations, 49(7), 977-993.

18.Soo, Hoi Sin., Ali, Hassan.,(2017). Can Stressed Employee Perform Organizational 
Behavior? Journal of Advanced Management Science Vol. 5, No. 2, March 2017

19.Wayne, S. J., Shore, L. M., and Liden, R. C. (1997). Perceived organizational support and leadermember exchange: A social exchange perspective. Academic of Manajement Journal, 40(1), 82-111.

20. Yogamalar,I.,Samuel,Anand.A.,(2016).

Shared Value and Organizational Citizenship Behavior of Generational Cohort : A Review and Future Directions. Management, Vol. 21, 2016, 2, pp. 249-271 